\title{
Fatigue safety examination of a riveted railway bridge using data from long term monitoring
}

\author{
Eugen BRÜHWILER \\ Professor, Dr Civil Engineer \\ Ecole Polytechnique (EPFL) \\ Lausanne, Switzerland \\ eugen.bruehwiler@epfl.ch \\ Christian MEYER \\ M.Sc. Engineer in geology \\ Terra Monitoring \\ Zurich, Switzerland \\ meyer@,terra.ch
}

\author{
Max BOSSHARD \\ Civil Engineer ETH \\ Flückiger + Bosshard Consult. \\ Zurich, Switzerland \\ max.bosshard@fbag.ch
}

\author{
Marcel TSCHUMI \\ Dr h.c. Civil Engineer ETH \\ Zollikofen, Switzerland \\ marcel.tschumi38@bluewin.ch
}

\author{
Pirmin STECK \\ M.Sc. Civil Engineer \\ Flückiger + Bosshard Consult. \\ Zurich, Switzerland \\ primin.steck@fbag.ch
}

\author{
Senta HALDIMANN \\ Dr Civil Engineer \\ Swiss Federal Railways \\ Bern, Switzerland \\ senta.haldimann@sbb.ch
}

\section{Summary}

Long term monitoring of structural elements of a 115 years old riveted railway bridge structure of high value as cultural heritage has been conducted. Monitored values were exploited by Rainflow analysis and served as the basis for the fatigue safety verification. As the locations of measurements are generally not identical with the cross sections of verification, measured strains were translated to the relevant verification cross section by means of factors that were determined by structural analysis. Using these values, all fatigue relevant structural details were first verified with respect to the fatigue limit. Then, damage accumulation calculation according to the Palmgren-Miner Rule was performed for those elements where the fatigue limit check was not fulfilled. Sufficient fatigue safety could finally be verified for the entire riveted structure and additional service duration of at least 50 years for this riveted structure could be validated.

Keywords: Fatigue safety, service life, riveted steel bridge, structural health monitoring, examination.

\section{Introduction}

Riveted bridges were built over a period of more than 100 years up to the 1950 s. There are thousands of riveted bridges around the world in service. Some of them are considered historical and should be preserved as architectural heritage. Often, an important remaining service life may be identified such that economically, it is not justified to replace a bridge because of some age criterion.

Bridges are built to serve several generations of users. As part of the transportation infrastructure, bridges add value to the public economy. Therefore, there is a high interest in their efficient economic performance while providing the intended utilisation without any restriction (e.g. traffic load limitations). Also, the safety of the individual and of society need to be considered in a wellbalanced manner for the bridge and its significance within a given transportation system.

This paper deals with the examination of a riveted railway bridge structure which is in service for 115 years. Due to ever increasing traffic demands the fatigue safety and service duration of the bridge was assessed some years ago. This assessment led to the conclusion that the riveted steel structure would need significant strengthening interventions. Due to the excessive direct and indirect costs that such an intervention would produce, it was decided to conduct an examination with detailed investigation of structural behaviour by installing a long term monitoring system. The main objective was to verify the structural and fatigue safety of the riveted structure in view of a long further utilisation period of the structure while preserving the significant values as cultural heritage of the bridge. This paper outlines the methodology that explicitly considers monitored data and presents the main results of the examination of fatigue safety. 


\section{General methodology}

Examination of this bridge structure is performed following the principles of the Swiss Standards for existing structures enforced by the Swiss Society of Engineers and Architects (SIA) [1, 2]. These standards provide the regulative basis the structural engineer in Switzerland can rely on to deal professionally with existing structures. These principles lead to a methodology inherent to existing structures which has already been successfully applied over the last 20 years. Yet, many structural engineers nowadays still apply codes valid for the design of new structures to assess existing structures. This is fundamentally wrong and often leads to unnecessary and costly interventions. A change of paradigm is needed aiming the structural engineering community to clearly distinguish between codes for new and for existing structures.

The contemporary approach to existing structures is based on updating, which means collecting and exploiting detailed in-situ information from the existing structure while reducing uncertainties in structural parameters. The controlling parameters are determined as precisely as needed, and the structural safety is verified using so-called updated values for actions (loads) and resistance. In this way, it can often be shown that an existing bridge structure may be subjected to higher traffic loads while meeting the safety requirements and hence strengthening interventions are avoided.

\section{Description of the railway bridge}

The railway bridge across the River Rhine at Eglisau in Switzerland was built from 1895 to 1897 for single lane railway traffic. The central part of the $457 \mathrm{~m}$ long bridge is a riveted steel truss structure made of early mild steel. The truss girder has a span of $90 \mathrm{~m}$ and a height of $9 \mathrm{~m}$. Multiple arch approach viaducts in natural stone masonry with piers up to $50 \mathrm{~m}$ in height follow in the north and south of the steel truss (Fig. 1).

In 1982/83, the original carriageway (that consisted of a ballasted track on Zores iron profiles) was replaced by a steel trough with ballast. Several joints of the truss girder were also strengthened using posttensioned bolts, and the corrosion protection painting of the steel construction was renewed entirely.
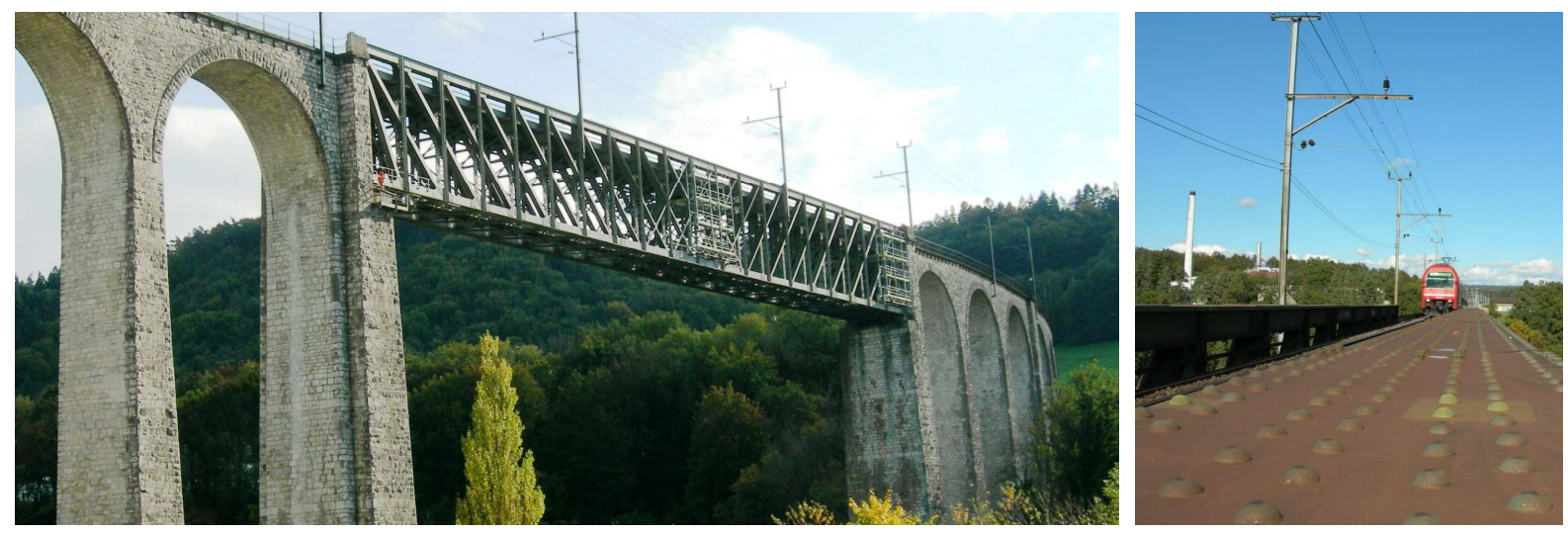

Figure 1: Railway bridge across the River Rhine at Eglisau, Switzerland

\section{Model for structural analysis}

In the first phase of this study, the truss structure was modelled by means of a three-dimensional bar model in order to determine sectional forces necessary for structural safety verification (Fig. 2). Since the carriageway (consisting of the trough, cross girders and floor beams) is located approximately $1.5 \mathrm{~m}$ below the top chord of the main girder, it contributes to the global structural behaviour by carrying significant compression forces in addition to the top chord. Consequently, in the model for the structural analysis, the carriageway was placed at the same level together with the cross girder and the horizontal wind bracing. Forces are thus transferred at this level to the adjacent vertical posts of the main truss. The floor beams and the trough (that was modelled by means of four longitudinal beams with adapted stiffness) are connected eccentrically to the cross girders according to their real position (Fig. 2). 

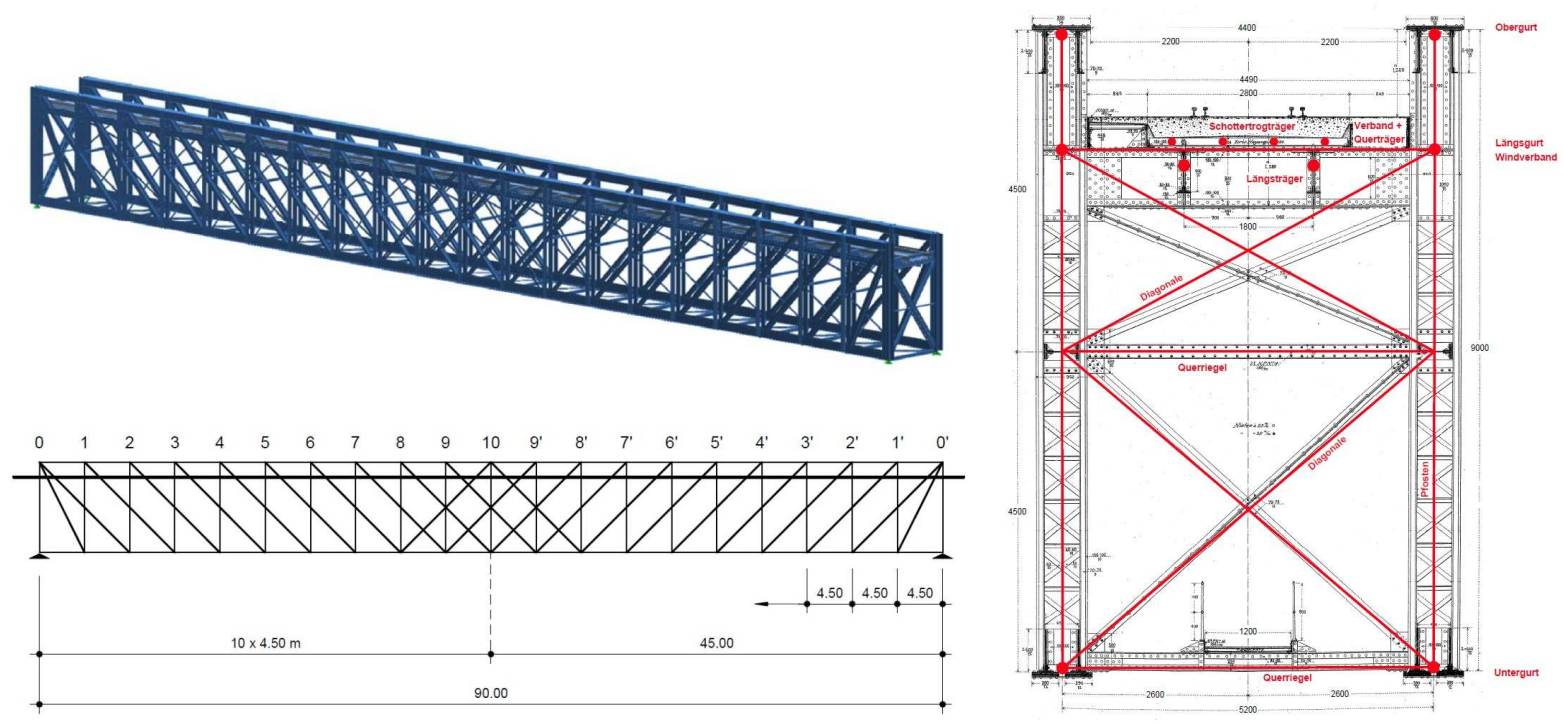

Figure 2: Three-dimensional bar model for the structural analysis with dimensions of the truss (left); cross section of the bridge girder and modelling (right)

The nodes of the main truss girder were modelled as fixed connections and eccentricity was taken into account. However, the bars of the upper and lower wind bracing as well as of the transverse bracings were modelled as pinned connections.

Comparison of the results from the load tests and structural analysis confirmed the adequacy of the structural model allowing calculating the structural behaviour with sufficient precision. The results also confirmed that with the installation of the trough in 1982 the stress state in the original floor beams was reduced significantly. Hence, it could be expected that the carriageway was not determinant with respect to fatigue.

\section{Monitoring}

\subsection{Arrangement of sensors}

The strain gauges relevant for the verification of the fatigue safety were mounted on structural elements and zones that are essentially subjected to tensile stresses in (Fig. 3):

- Field 1 on the two tensile diagonals and posts of the main truss and on the trough, floor beams and cross girders of the carriageway, and

- Field 10 on the lower chord at mid-span.
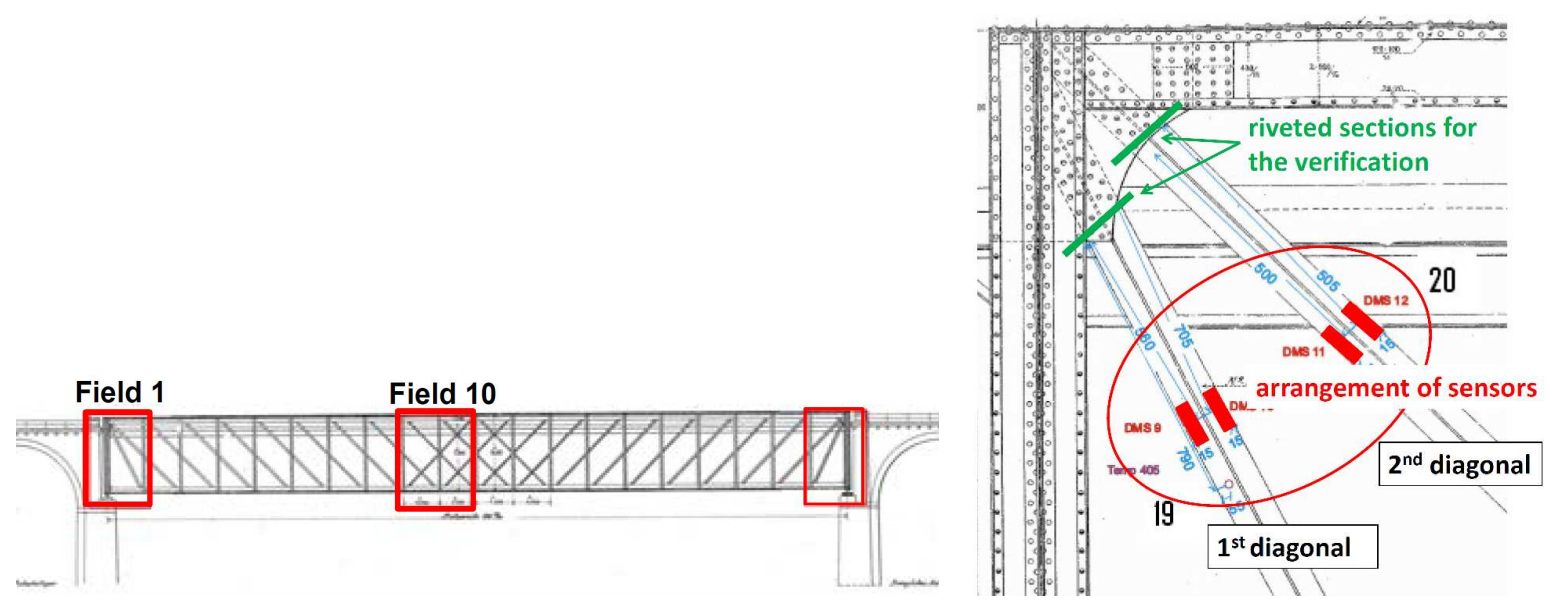

Figure 3: left: Localisation of the strain gauges relevant for the fatigue safety verification; right: location of sensors and verification sections of diagonals in Field 1 
In addition to the criterion of having good accessibility, strain gauges were placed such that strain distribution in the measured cross section corresponds most likely to gross section stresses (Fig. 3 right). This means, that the measuring locations lie as far away as possible from rivet holes or other "hot spots", to avoid measuring any stress concentration close to rivets.

In the following and as examples, some cross sections with the arrangement of strain gauges are presented (Fig. 4 left):
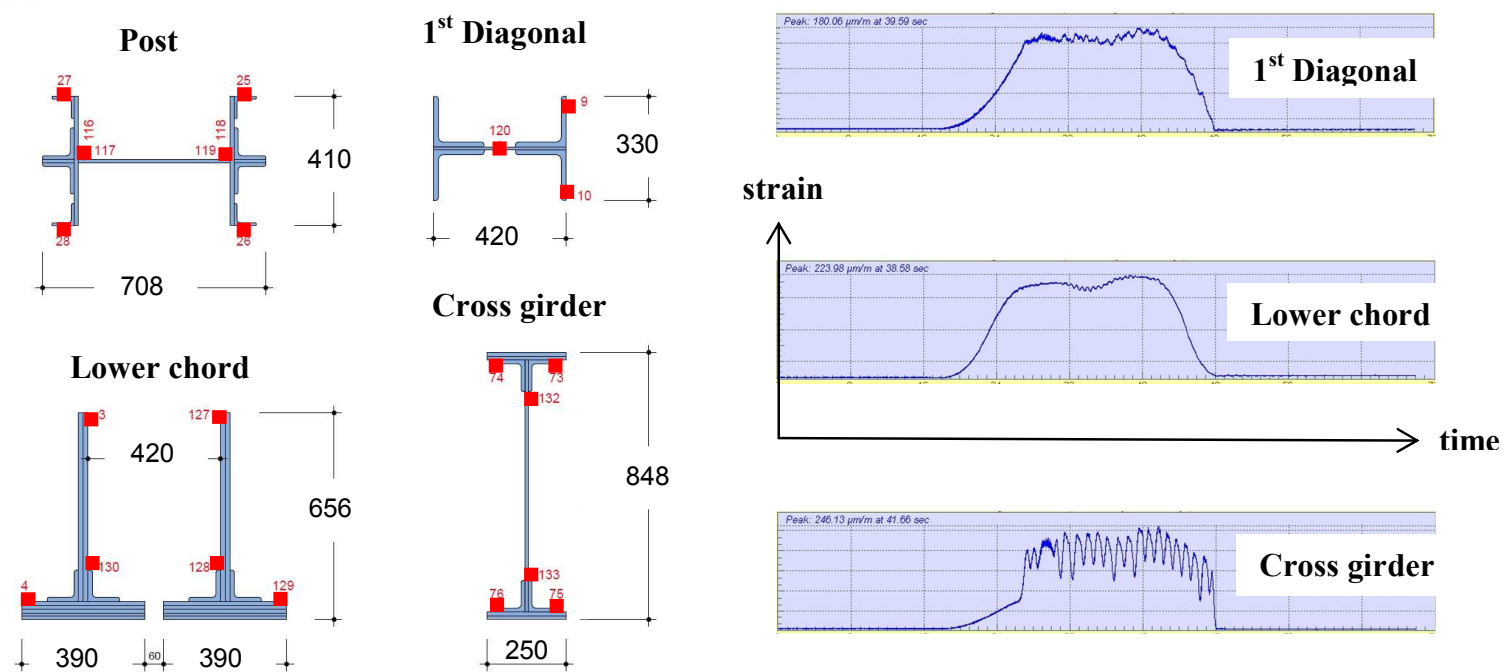

Figure 4: left: Arrangement of strain gauges in cross sections; right: Recorded data of one gauge on the 1st diagonal and lower chord of the truss girder as well as on a cross girder.

\subsection{Measurements}

The strain readings of all sensors due to the passage of every train, including passenger and freight trains, were recorded over a period of 12 months. As an example, Figure 4 (right) shows the structural response (as a function of time) of various elements due to the passage of a freight train. As expected, the results depict the small influence of single axle loads on diagonals and lower chord of the truss girder, while the strain readings for the cross girder show first a continuous increase (due to the global load bearing behaviour) followed by the distinct effect of the passage of each axle with rather large strain variations (local load bearing behaviour).

In order to verify the correct functioning of the measuring equipment and to calibrate the model for the structural analysis, load tests with three locomotives (with precisely known axle loads) were performed in September 2010, prior to the long-term monitoring measurement campaign.

Comparison of the measured results with the results obtained from structural analysis allowed for optimization of the measuring system by installing some additional sensors in fatigue relevant zones.

Analysis of recorded data confirmed that the fully automatic monitoring system allowed for reliable long term readings that could be exploited as a basis for the verification of fatigue safety.

\subsection{Mining of monitored data}

Monitored raw data from every train passage were exploited by means of Rainflow analysis, i.e. stress ranges were assigned to selected strain (stress) range groups and the number of strain ranges per group was counted. All monitored values were added over one calendar month, stored on Excel tables. Finally, the results from all 12 months of monitoring were summed up.

Figure 5 shows graphically presented histograms for the two analysed diagonals. The large majority of recorded stress ranges are below or equal to $50 \mathrm{MPa}$. Over the whole monitoring period, only several hundred stress range values larger than the constant amplitude fatigue limit of riveted details described by fatigue category 71 (Fig. 6) were recorded for the most fatigue relevant structural element. 


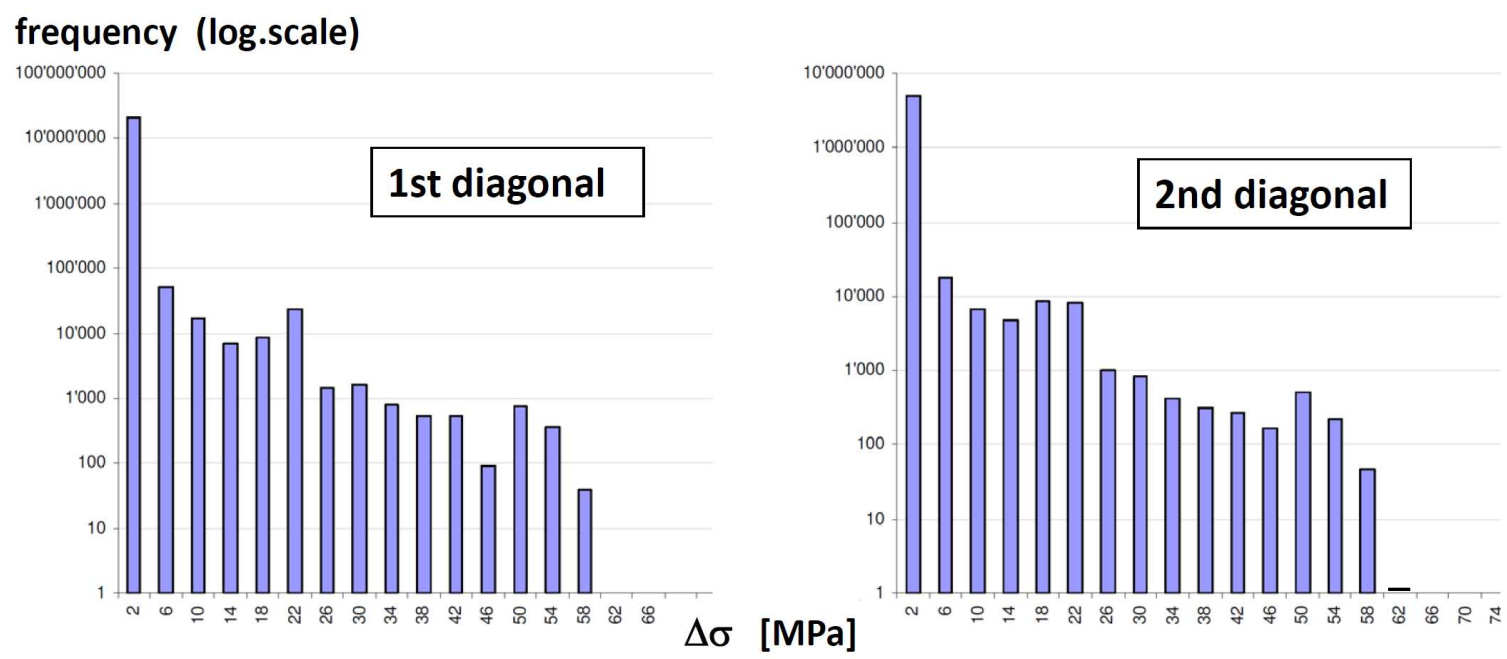

Figure 5: Histograms of a compilation of stress ranges over the whole monitoring period of the two diagonals of the main truss girder

\section{Fatigue safety verification}

\subsection{Procedure}

Fatigue safety is verified for determinant cross sections (details) with rivets. Since the location of the strain sensors were intentionally chosen to avoid measuring any stress concentration near rivets, monitored strain (stress) values need to be translated to the determinant rivet positions of the cross sections relevant for verification (Fig. 3 right). Consequently, conversion factors were determined for each verified cross section using the calibrated model for structural analysis. For this, a specific loading configuration was chosen to determine the sectional forces due to a loading configuration representing the load model for Line Class D4 according to the Swiss standards for existing structures $[3,4]$. Moreover, as tensile stresses obtained from monitored values are valid for gross sections, the conversion factor also considers net sectional areas in sections with rivet holes. These conversion factors were then applied to the monitored values to obtain stress range values for the fatigue safety verification.

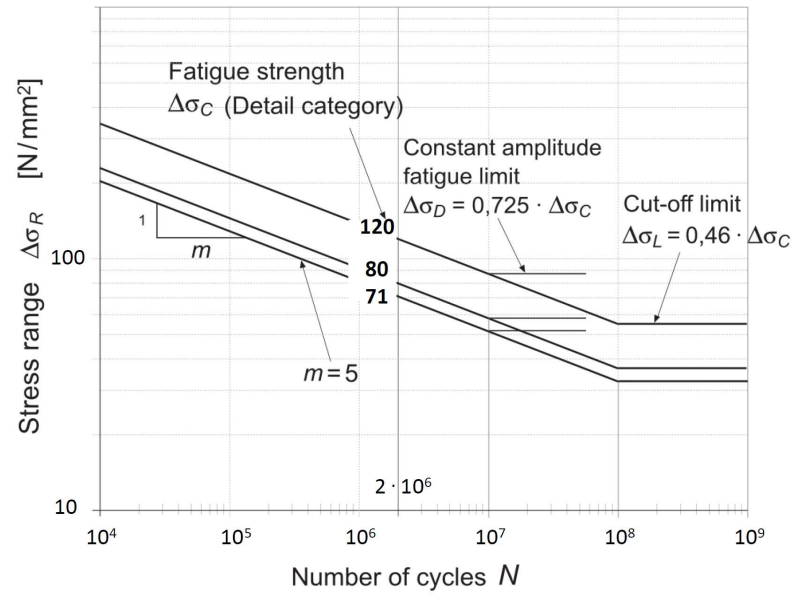

Figure 6: Fatigue strength for riveted structural details, according to [3]

Fatigue safety was verified with respect to fatigue resistance for riveted details as given in $[5,6]$ (Fig. 6). Fatigue category of $80 \mathrm{MPa}$ was considered for the posts of the main truss as well as for the cross girders and the floor beams while fatigue category of $71 \mathrm{MPa}$ was taken into account for the diagonals and the lower chord of the main truss girder. This fatigue resistance is to be compared with stress ranges calculated using net-section stresses.

The fatigue resistance given in Fig. 6 is considered to be rather conservative in particular in the domain of low stress ranges and high numbers of cycles which is the relevant domain in the present case. Indeed, constant-amplitude fatigue limit of riveted members was estimated to be at a stress range level of $70 \mathrm{MPa}$ based on fatigue tests up to 20 million cycles [7]; more research is needed to explore more in detail the fatigue behaviour of riveted details at high numbers of cycles. The fatigue strength of rivets in shear is not determinant in the present case as a shear stress range of $100 \mathrm{MPa}$ may be taken as a constant-amplitude fatigue limit [7]. 
Verification of fatigue safety followed a stepwise procedure: In a first step, the fatigue safety was checked with respect to the fatigue limit, i.e. maximum stress range was compared with the constant amplitude fatigue limit of the riveted detail. Only when fatigue safety could not be verified on the first level, in a second step, fatigue damage accumulation calculation by applying the PalmgrenMiner approach was conducted.

\subsection{Step 1: Fatigue safety verification with respect to the fatigue limit}

For every fatigue relevant verification section, the maximum monitored value of stress range (that are all fully in the tensile domain except for the post of the main truss) over the whole monitoring period was translated into maximum stress range for the verification using the corresponding conversion factor. The results are given in Table 1. The fatigue safety is verified if the degree of conformity $n$ according to $[1,2]$, i.e., the ratio of fatigue limit to maximum fatigue stress range, is equal to or larger than 1.0.

Table 1: Results of the verification with respect to the fatigue limit for the determinant structural elements

\begin{tabular}{|c|c|c|c|c|c|}
\hline Structural element & $\begin{array}{l}\text { monitored } \\
\text { max. stress } \\
\text { range } \\
\quad[\mathrm{MPa}]\end{array}$ & $\begin{array}{l}\text { Conver- } \\
\text { sion factor }\end{array}$ & $\begin{array}{l}\text { max. stress } \\
\text { range (verific. } \\
\text { section) } \\
\Delta \sigma_{\max }[\mathrm{MPa}]\end{array}$ & $\begin{array}{l}\text { Fatigue limit } \\
\qquad \Delta \sigma_{D} \\
{[\mathrm{MPa}]}\end{array}$ & $\begin{array}{l}\text { Degree of } \\
\text { conformity } \\
n=\frac{\Delta \sigma_{D}}{\Delta \sigma_{\max }}\end{array}$ \\
\hline \multicolumn{6}{|l|}{ Carriageway: } \\
\hline Floor beam (at mid-span) & 38 & 1.43 & 54 & 58 & 1.07 \\
\hline Cross girder (at mid-span) & 34 & 1.18 & 40 & 58 & 1.44 \\
\hline Cross girder (connection with truss) & 30 & 1.60 & 48 & 51 & 1.07 \\
\hline \multicolumn{6}{|l|}{ Main truss girder: } \\
\hline Post (mostly compression stresses) & 58 & 1.12 & 65 & 58 & 0.89 \\
\hline $1^{\text {st }}$ diagonal & 58 & 1.71 & 99 & 51 & 0.52 \\
\hline $2^{\text {nd }}$ diagonal & 62 & 1.33 & 82 & 51 & 0.62 \\
\hline Lower chord at mid-span & 46 & 1.20 & 55 & 51 & 0.93 \\
\hline
\end{tabular}

All except four sections pass the fatigue safety check with respect to the fatigue limit. Consequently, these four insufficient sections are verified on the next verification level according to Step 2.

Mounting of the steel trough in 1982 led to a change of the stress state in the original structural elements of the carriageway. The original floor beams were unloaded as they are no longer loaded directly by axle loads; they now carry stresses essentially due to the global behaviour of the structure. Consequently, stresses in the connection of the floor beams with the cross girders were also reduced which explains why the fatigue safety verification of this detail (which usually is the fatigue determinant structural detail of riveted railway bridge structures in particular with open decks) could be easily fulfilled.

\subsection{Step 2: Fatigue damage accumulation calculation and fatigue safety verification}

Structural elements with unsatisfied fatigue safety check at the first level, namely the first and second diagonals as well as the lower chord of the main truss girder, were investigated by means of Palmgren-Miner damage accumulation method using the S-N curves for riveted details (Fig. 6). Stress ranges below the cut off limit were neglected. (As fatigue relevant stresses in the posts are mostly in compression, verification of these elements is not presented in this paper.)

In a first step, fatigue damage over the 12 months of monitoring (April 2011 - March 2012, average of 159 trains per day) was determined. Histograms of stress range as obtained from Rainflow analysis were translated to the verification sections by applying the conversion factors. Then, for each stress range $\Delta \sigma_{i}^{m}$, the maximum number of cycles $N_{i}$ was determined as follows:

$N_{i}=\frac{\Delta \sigma_{c} \cdot 2 \cdot 10^{6}}{\Delta \sigma_{i}^{m}}$

with $\Delta \sigma_{c}$ being the fatigue strength at 2 million cycles. The measured number of cycles $n_{i}$ for each stress range was then used to determine the theoretical fatigue damage $d_{i}$ per stress range: 
$d_{i}=\frac{n_{i}}{N_{i}}$

And by summing up over all $k$ stress ranges, the total damage $D$ is obtained:

$D=\sum_{i=1}^{k} d_{i}$

Fatigue failure is supposed to occur if the total damage reaches a value of $D=1.0$.

Past traffic was modelled using the load models valid for the respective allowable Line Classes as defined by the European Railways [4]. During the initial phase of service, railway traffic similar to Line Class B2 was allowed. With the electrification in 1928, traffic loads were increased to Line Class C3. With the modification of the carriageway in 1982, the Line Class was again increased to D4. In addition, reliable data was available regarding train numbers and gross register tonnage (GRT) per year from the statistical yearbooks of the Swiss Railways. With this data, fatigue solicitation of the bridge during the past service period from 1897 to 2011 could be estimated with good precision. For the future railway traffic, a scenario for the expected traffic in terms of number of trains and GRT was developed in accordance with the Swiss Railways and considered to forecast cumulated fatigue damage for the future. This led to the results shown in Table 2.

Table 2: Total projected fatigue damage for the determinant structural elements

\begin{tabular}{lccc}
\hline Structural element & \multicolumn{3}{c}{ Cumulated fatigue damage until year } \\
\cline { 2 - 4 } & 2012 & 2035 & 2065 \\
\hline $1^{\text {st }}$ diagonal & 0.133 & 0.247 & 0.420 \\
\hline $2^{\text {nd }}$ diagonal & 0.025 & 0.045 & 0.075 \\
\hline Lower chord at mid-span & 0.002 & 0.003 & 0.006 \\
\hline
\end{tabular}

A maximum value of theoretical fatigue damage of 0.42 in the year 2065 was obtained for the first diagonal of the main truss girder while for the second diagonal and the lower chord at mid-span much smaller accumulated damage was calculated. All values are however significantly lower than the theoretical value of $D=1.0$ for fatigue failure.

The forecasted maximum cumulated damage value of 0.42 in 50 years from now is considered to provide an acceptable safety margin with respect to fatigue failure. Actually, as no partial safety factors have been explicitly applied on fatigue action effect and fatigue resistance values, the project team accepted a safety criterion given by a damage value of 0.50 as being acceptable to provide a sufficient safety margin with respect to theoretical fatigue failure of the element.

\subsection{Discussion and recommendation}

The fatigue safety verifications based on the monitored values show sufficient fatigue safety for the entire riveted structure for at least the next 50 years of service duration. Also, the structural elements having priority during inspections were identified.

As the determinant structural element, i.e. the $1^{\text {st }}$ tension diagonal of the main truss, showed the by far highest theoretical fatigue damage value, it is recommended to strengthen this structural element in the near future. By performing this intervention which has a preventive character and is not costly, very long future service duration (going well beyond 50 years) could be expected and attributed to the entire riveted structure, while taking into account the significantly more intense fatigue solicitation due to increasing traffic demand in the future.

Moreover, information and data regarding the railway traffic and the calculated fatigue damage (table 2) actually indicate that the riveted structure was exposed to a relatively low fatigue solicitation during its past service duration of 115 years. In fact, the structure is virtually still in an undamaged condition in terms of fatigue, and only the future higher railway traffic loading may produce some fatigue damage in certain structural elements.

A 115 year old bridge is commonly considered to be "old" and a thus often condemned to be a candidate for replacement. The present example shows however again, that a change in paradigm is badly needed when considering the notion of service duration: there is no "old" bridge, and solely 
the structural performance (and not the age of a structure) is the relevant and adequate criterion.

\section{Conclusions}

A case study based on a novel methodology for fatigue safety verification is presented leading to the following conclusions:

- The suggested methodology to verify the fatigue safety allows for explicit consideration of data from long term monitoring.

- Monitored data allow for accurate determination of fatigue relevant stresses in fatigue prone bridge structures.

- The results show that applying this methodology, the fatigue safety of the riveted railway bridge was verified also after 115 years of service duration, and long future service duration may be expected taking into account the expected higher traffic loading.

The present approach is economic as the cost for the long term monitoring and accompanying theoretical studies is only a small fraction of the cost of a hypothetical major strengthening or bridge replacement project which could thus be avoided by this study.

\section{References}

[1] Brühwiler, E., Vogel, T., Lang, T., Lüchinger, P. 2012. Swiss standards for existing structures, Structural Engineering International, IABSE Zurich, Volume 22, Nr 2.

[2] SIA 269, 2011. Existing structures - Bases for examination and interventions, Swiss Society of Engineers and Architects (SIA), Zurich.

[3] SIA 269/1, 2011. Existing structures - Actions, Swiss Society of Engineers and Architects (SIA), Zurich.

[4] UIC Code 700, 2004. Classification of lines and resulting load limits for wagons, 9th edition of 1.7.87 and 2 Amendments, revision 2003/4, International Union of Railways.

[5] SIA 269/3, 2011. Existing structures - Steel structures, Swiss Society of Engineers and Architects (SIA), Zurich.

[6] Taras, A., Greiner, R. 2010. Development and Application of a Fatigue Class Catalogue for Riveted Bridge Components, Structural Engineering International, IABSE Zurich, Volume 20, Nr 1, 91- 103.

[7] Brühwiler, E., Smith, I., and Hirt, M. (1990). "Fatigue and Fracture of Riveted Bridge Members.” ASCE J. Struct. Eng., 116(1), 198-214, 1990. 